\title{
Verificación en la infodemia de la Covid-19. El caso Newtral
}

\section{Verification in the Covid-19 infodemic. Newtral's case study}

Guadalupe Aguado-Guadalupe. Universidad Carlos III de Madrid. España.

maguado@hum.uc3m.es

$[\mathrm{CV}] \mathrm{C}$

Itziar Bernaola-Serrano. Universidad Carlos III de Madrid. España.

ibernaol@hum.uc3m.es

$[\mathrm{CV}] \bigcirc$

\section{Cómo citar este artículo / Referencia normalizada}

Aguado-Guadalupe, G. y Bernaola-Serrano, I. (2020). Verificación en la infodemia de la Covid-19. El caso Newtral. Revista Latina de Comunicación Social, 78, 289-308. https://www.doi.org/10.4185/RLCS-2020-1478

\begin{abstract}
RESUMEN
Introducción: En este trabajo se describen los procedimientos de verificación de Newtral en la infodemia acontecida durante la crisis de la Covid-19 y las características de los contenidos verificados. Metodología: Se analizan 205 contenidos verificados entre el 25 de enero y el 25 de mayo de 2020, se hace un seguimiento de los procesos de verificación y se realiza entrevista personal no estructurada con el director de contenidos de Newtral. Resultados: El número de contenidos verificados aumentó considerablemente a partir del 10 de marzo, cuatro días antes de decretarse el estado de alarma. En cuanto a los sistemas de verificación, en el 90,5\% de los casos se recurrió a consulta de fuentes, empleándose herramientas solamente en el 9,5\%. Lo más difundido fueron textos en redes sociales, detectándose el $66 \%$ de los casos en más de una red social. Fue imposible detectar el origen en el $91,7 \%$ de los contenidos contrastados. Discusión y conclusiones: La consulta a diversas fuentes fue el método de verificación más utilizado, muy por delante de herramientas como motores de búsqueda o de geolocalización. Prevalecieron las consultas a fuentes oficiales y suplantadas. Lo más habitual fueron contenidos fabricados e impostores difundidos a través de redes sociales y WhatsApp.
\end{abstract}

PALABRAS CLAVE: Covid-19; Newtral; verificación; infodemia; desinformación; contenidos falsos; fact-checking.

\begin{abstract}
Introduction: This work describes Newtral's verification procedures in the infodemic that occurred during the Covid-19 crisis and the characteristics of the verified contents. Methodology: 205 verified contents published between January 25 and May 25, 2020, are analyzed; verification processes are followed up and an unstructured personal interview with Newtral's director of content is conducted. Results: The number of verified contents increased considerably as of March 10, four days before the state of alarm was ordered. Regarding verification methods, sources were consulted in $90.5 \%$ of cases, while technological tools were only used in $9.5 \%$. The most widespread were
\end{abstract}


texts on social media, detecting $66 \%$ of cases in more than one. It was impossible to detect the origin in $91.7 \%$ of the verified contents. Discussion and conclusions: Consulting various sources is the most widely used verification method, well ahead of tools such as search engines or geolocation apps. Consultations to official and supplanted sources prevailed. The most common were manufactured and impostor contents distributed through social media and WhatsApp.

KEYWORDS: Covid-19; Newtral; verification; infodemic; disinformation; fake content; factchecking.

CONTENIDOS. 1. Introducción. 1.1. Contenidos falsos y verificación. 2. Metodología y preguntas de la investigación. 3. Resultados. 3.1. Métodos de verificación empleados por Newtral. 3.2. Evolución temporal de las verificaciones realizadas por Newtral. 3.3. Formato de los contenidos falsos. 3.4. Canal de difusión. 3.5. Origen de los contenidos verificados. 3.6. Tipología de los contenidos. 3.7. Riesgos que comportan los contenidos falsos verificados. 4. Discusión. 5. Conclusiones. 6. Bibliografía.

\section{Introducción}

Las primeras informaciones aparecidas en España sobre una neumonía atípica, que posteriormente conoceríamos como la Covid-19, se publicaron a principios de enero de 2020 (Aldama, 2020; De la Cal, 2020; Santirso, 2020). A partir de ese momento la importancia de los sistemas de verificación se ha acrecentado como consecuencia del incremento de contenidos falsos y la desinformación originada durante la crisis de la Covid-19, dando lugar a lo que Tardáguila ha calificado como "la peor ola de desinformación de la historia" (Valera, 2020). Un claro ejemplo de esta situación es que, durante la pandemia, el número de consultas que llegaban a Newtral a través de su servicio de verificación bajo demanda vía WhatsApp se multiplicó por 16. Según explica Joaquín Ortega, director de contenidos de dicha empresa, hubo que reorganizar todo el equipo de verificación y centrarlo en afrontar el volumen de solicitudes de gente que necesitaba certezas en uno de los momentos de mayor incertidumbre vividos en las últimas décadas.

Si bien es cierto que se contaba con experiencias previas en este sentido, como la vivida a raíz de la crisis sanitaria del virus del Ébola en 2014, momento en el que se puedo apreciar una corriente de difusión de bulos en Internet, especialmente a partir del primer caso que se detectó fuera de África. Situación que originó lo que Jurado-Salván y Jurado-Izquierdo (2014) denominaron "el efecto Guadiana" de la información sanitaria, en tanto que se dio "primero, crisis; luego, alarma sanitaria; después, desinformación” (Jurado-Salván y Jurado-Izquierdo, 2014, p.90).

Posiblemente la difusión de contenidos falsos durante esta nueva crisis sanitaria se ha visto favorecida por tratarse de un contexto en el que se cumplen las 8P o motivos de desinformación identificados por First Draft (Wardle, 2017): periodismo deficiente, parodia, provocación, pasión, partidismo, provecho, poder o influencia política, y propaganda. A ello se une el que las informaciones falsas se difunden "más lejos, más rápido y de forma más amplia" (Vosoughi, Roy y Aral, 2018).

Dicha situación de sobreabundancia informativa, su rápida propagación y la desinformación originada durante la pandemia, han provocado que la Organización Mundial de la Salud (OMS) tuviera que advertir sobre la amenaza de los rumores, bulos y datos falsos que se estaban propagando, dando lugar a lo que ha denominado infodemia. La situación llevó a la OMS a poner en marcha un equipo de comunicación de riesgo y gestión de infodemias para rastrear activamente la información, al tiempo que habilitaba en su web un apartado para desmentir los mitos que circulaban 
por redes sociales. Por su parte, el Gobierno de España realizó la campaña "Coronavirus, siempre fuentes oficiales", para prevenir a la población (Martín-Barato et al., 2020). A ello se han unido las estrategias de WhatsApp, Twitter y Facebook para luchar contra dichas noticias falsas. En esta línea, la red de verificación International Fact-Checking Network (IFCN) puso en marcha un proyecto para combatir la desinformación en WhatsApp durante la pandemia, con el que conectaba a los usuarios con más de 80 verificadores independientes de 74 países.

Según la directora asociada de la IFCN, Cristina Tardáguila, el coronavirus es el mayor reto al que se han enfrentado los fact-checkers (Suárez, 2020). Se puede afirmar que la pandemia de bulos y desinformación en torno a la Covid-19 es global. Más de 100 equipos de fact-checkers de diferentes países, entre ellos el equipo de Newtral, trabajan para combatir esta infodemia. Asimismo, según indica el director de contenidos de la organización, Joaquín Ortega, Newtral colabora con la alianza internacional de verificadores contra la desinformación sobre el coronavirus del IFCN. Además, gracias a la colaboración con Facebook, han logrado desarrollar un chatbot para que los usuarios de WhatsApp puedan encontrar ahí los desmentidos publicados por todos los miembros de la alianza, tanto en inglés como español.

En el presente trabajo se analizan los métodos de verificación utilizados por Newtral durante la crisis sanitaria de la Covid-19 y cuáles son las características de los contenidos verificados.

Se ha seleccionado esta startup, fundada en 2018, por ser uno de los equipos de fact-checkers españoles que han obtenido la certificación de la International Fact-Checking Network -junto con Maldita.es, Efe Verifica y AFP España- y que ha colaborado en una alianza junto a otros miembros de la IFCN para combatir la desinformación a nivel global durante la pandemia. Es relevante destacar que todos estos fact-checkers deben someterse a una revisión anual por la IFCN para comprobar que cumplen con una serie de criterios recogidos en su Código de Principios (https://ifcncodeofprinciples.poynter.org/), en cuanto a la financiación, imparcialidad y transparencia en metodología y fuentes, de forma que todos ellos manejan unos estándares comunes en su forma de trabajar, por lo que los resultados de esta investigación en cuanto a la verificación realizada por Newtral durante la pandemia pueden ser en buena medida extrapolables a otros verificadores.

El estudio se ha centrado en los 205 contenidos falsos que fueron verificados por Newtral entre el 25 de enero de 2020, fecha en que Newtral detectó el primer contenido falso relacionado con el coronavirus, y el 25 de mayo de 2020, fecha en la que todas las provincias españolas salieron de la fase cero.

Los objetivos de la investigación son:

1. Detallar los parámetros, métodos y herramientas de verificación utilizados por Newtral en el caso de los contenidos falsos relacionados con la Covid-19.

2. Analizar las características de los contenidos falsos verificados por Newtral durante la infodemia en cuanto a número, formato, canal de difusión, origen, tipología y posibles riesgos para la sociedad.

3. Comprobar si los datos resultantes de los procesos de verificación permiten observar cambios significativos en cuantía de contenidos y tipología de los mismos a lo largo de la pandemia.

\subsection{Contenidos falsos y verificación}

Si bien los contenidos falsos, sin contrastar y bulos han existido siempre, se puede decir que son un problema que ha proliferado en el entorno digital, entre otras cuestiones porque como señala Elías $(2018$, p.2) "en la segunda década del siglo XXI la verdad ya no es tan relevante, porque importan más los seguidores o las entradas que el prestigio de la fuente o del profesional que firma". A ello se 
ha unido la aparición de portales de intoxicación informativa a partir de bulos y la rápida viralización, acrecentando la desinformación y pérdida de credibilidad. Esto ha llevado a plantearse cuáles son las causas que originan dichos contenidos falsos y las consecuencias que provocan, teniendo en cuenta cómo influyen en su difusión factores como las redes sociales, y lo que su proliferación supone tanto para los medios de comunicación como para la ciudadanía (McNair, 2018).

Precisamente la difusión de contenidos falsos durante la crisis de la Covid-19 ha propiciado un interés investigador sobre el tema, abordando su impacto en el sistema mediático, en cuanto a capacidad de detección y credibilidad (Casero-Ripollés, 2020); su difusión en plataformas como Twitter, Instagram, YouTube, Reddit y Gab (Cinelli et al., 2020) y la tipología de los mismos (Brennen et al., 2020). Todo ello sin perder de vista el análisis de qué ha motivado la difusión de fake news durante la pandemia, observándose el papel que juega la falta de atención de los usuarios de redes sociales en el contexto de la desinformación, lo que ha llevado a plantearse la necesidad de mejorar la precisión de la información sobre la pandemia (Rand et al., 2020).

Si bien es cierto que la infodemia originada durante la crisis sanitaria ha incrementado el interés por el análisis de los contenidos falsos, éstos ya venían siendo objeto de estudio en cuanto a la globalidad de la problemática (Pérez-Tornero y Varis, 2010), alcance terminológico (Wardle y Derakhshan, 2017) y delimitación conceptual, llevando por ejemplo a plantearse los matices diferenciadores entre fake news y posverdad (Blanco-Alonso, 2020).

En lo que respecta a cuestiones de índole terminológica cabe matizar que a pesar de que diversos autores (Wardle, 2017; Zuckerman, 2017; Boyd, 2017 y Jack, 2017) han calificado el término fake news de inadecuado para describir un fenómeno tan complejo como el de la misinformación y desinformación (Wardle y Derakhshan, 2017), el término fake news está presente en una mayoría de los artículos más citados de la Web of Science, y Scopus (Blanco-Alfonso et al., 2019).

Otros aspectos que han merecido atención en las investigaciones centradas en contenidos falsos han sido el enfoque y contenido de los mismos, para conseguir que las noticias falsas sean más propensas a que la gente las comparta digitalmente que las reales (Vosoughi, Roy y Aral, 2018). Precisamente, entre las variables que influyen en su difusión, se han detectado: la confianza en la información compartida, la confianza en los medios de comunicación y la credibilidad de las noticias falsas (Montero-Liberona y Halpern, 2019).

Justamente, la facilidad de propagación y viralización ha llevado a que en las diversas investigaciones que se han realizado al respecto se remarque la necesidad de alfabetización mediática, en tanto que "si las nuevas generaciones obtienen su información de redes sociales y otros recursos en línea deben aprender a decodificar lo que leen” (Fernández-García, 2017, p.75).

Se ha señalado igualmente la importancia de la detección ante el potencial de tener impactos extremadamente negativos sobre los individuos, si bien hay que ser conscientes de que es una labor desafiante (Shu, et al., 2017). Téngase en cuenta que las noticias falsas constituyen un problema difícil de abordar, inclusive con las herramientas de detección disponibles, debido a que "el análisis lingüístico, terminológico y semántico se basa en el estudio de frecuencias y expresiones que pueden ser medidas y contrarrestadas" (Blázquez-Ochando, 2018, p.15), a ello se une el dilema de la detección en tiempo real. Por ello, hay autores que reflexionan sobre la conveniencia de un marco regulador, llegando a plantear dos perspectivas en este sentido: "1) la necesidad de regular los contenidos independientemente de la forma en la que éstos se presentan; 2) la necesidad de legislar de forma en la que se presentan los contenidos como un mecanismo de transparencia y de defensa de nuestros derechos como consumidores" (Magallón-Rosa, 2018a, p. 1). 
Otros aspectos que han merecido atención han sido el riesgo del filtrado y etiquetado de los contenidos (Pauner-Chulvi, 2018), su repercusión en resultados electorales (Allcott, 2017) y asuntos políticos (Aparici, García y Rincón-Manzano, 2019), así como su intencionalidad (Blanco-Herrero y Arcilla-Calderón, 2019).

Todo ello sin perder de vista los cambios que se han incorporado en las rutinas de trabajo (Rodríguez-Fernández, 2019) y el papel del periodismo como antídoto, teniendo presente que las noticias falsas empujan al periodismo hacia un nuevo escenario, donde "los medios deben comprender que luchar contra la desinformación y las noticias falsas exige una mayor capacitación de sus periodistas y una mayor transparencia en cuanto a política editorial" (Amorós-García, 2019, 40). Lo cual a su vez comporta la necesidad de nuevos perfiles profesionales (Ufarte-Ruiz, PeraltaGarcía y Murcia-Verdú, 2018), donde prime la formación en verificación de los redactores, las políticas de rectificación transparentes y ser útiles a la ciudadanía (Jiménez-Cruz, 2019). En todo caso hay que tener presente, como señala Cebrián-Enrique (2012, p. 238) que "el escenario de los medios sociales es una oportunidad para hacer valer el periodismo, en virtud de la verificación, entre otros valores".

Precisamente el aumento de contenidos falsos y su rápida viralización ha llevado a la necesidad de plantearse cómo combatirlos teniendo presente, como señala Redondo (2018), que verificar consiste en comprobar y contrastar. Si bien dicha verificación previa a la difusión se hace compleja en un entorno como el actual, en el que se tiene un rápido acceso a la información, pero también a la desinformación, como consecuencia de la viralización a través de las redes sociales (Ortiz de Guinea y Martín-Sáez, 2019). Por ello es necesario tener en cuenta, como señala Silverman (2014), que la tecnología puede llevarnos por mal camino tanto como nos puede ayudar cuando hay mucha información moviéndose a un ritmo muy rápido.

La importancia de la verificación se ha puesto de manifiesto en el interés que han adquirido las plataformas de identificación de bulos, dando lugar a estudios centrados en el funcionamiento de las mismas, tal es el caso del análisis sobre Maldita.es, en el que se ha podido apreciar la relevancia de los dispositivos móviles y de las redes sociales para el funcionamiento de este tipo de proyectos, así como la aplicación de un proceso riguroso de verificación múltiple para los desmentidos (BernalTriviño y Clares-Gavilán, 2019).

Atención han merecido igualmente las estrategias comunicativas de fact-checking, tanto en lo que respecta a desmentido de rumores como a tipología de desinformaciones que circulan (MagallónRosa, 2018b). Precisamente la desinformación ha llevado a que la verificación sea uno de los grandes retos informativos en los medios digitales que buscan ser referentes frente al consumo de contenidos en redes sociales (Marcos-Recio, 2017), al tiempo que ha supuesto una oportunidad a efectos de credibilidad para el periodismo, llevando a plantearse cómo revertir la situación desde el propio sector y qué riesgos y oportunidades tiene el periodismo en este contexto (Pérez-Rey y Calderón, 2019). Téngase en cuenta que sólo en la última década, con anterioridad a la pandemia de la Covid19, las plataformas de fact-checking se habían asentado en más de 50 países (Fernández-García, 2017).

Tampoco han sido ajenos al interés de los investigadores en este sentido los servicios de mensajería y redes sociales, tal es el caso de Twitter (Magallón-Rosa, 2018b), WhatsApp (Palomo y Sedano, 2018) y Facebook (Guess, Nagler y Tucker, 2019), que han merecido atención en cuanto a procesos de verificación, divulgación, e implicación de las audiencias en dicha tarea. 


\section{Metodología y preguntas de investigación}

La investigación se ha centrado en Newtral en tanto que el conocimiento de sus métodos de verificación tiene un valor en sí mismo y el volumen de casos analizados permite comprender el alcance y algunas características de la infodemia.

Las preguntas planteadas para conseguir los objetivos propuestos en este artículo son las siguientes:

P1. ¿Cuáles han sido los métodos de verificación utilizados por Newtral durante la crisis de la Covid -19 ?

P.2. ¿A qué tipo de fuentes se ha recurrido?

P.3. ¿Cuáles han sido las herramientas de verificación utilizadas?

P.4. ¿Cómo ha sido la evolución temporal de las verificaciones?

P.6. ¿Cuál ha sido el formato más habitual de los contenidos falsos detectados?

P.7. ¿Por qué canales se han difundido los contenidos?

P.8. ¿Se ha podido identificar el origen de los contenidos falsos verificados?

P.9. ¿Qué tipología de contenidos se han identificado?

P. 10. ¿Qué posibles riesgos ha comportado la difusión de dichos contenidos?

Para realizar el análisis se ha recurrido a una metodología de triangulación combinando análisis cualitativos y cuantitativos. Se ha efectuado un estudio de los procedimientos de verificación, un análisis de los contenidos verificados y se ha realizado una entrevista personal no estructurada al director de contenidos de Newtral.

El método responde a las siguientes fases:

1. Se han seleccionado 205 contenidos verificados por Newtral entre el 25 de enero de 2020 , fecha en la que dicha entidad verificó el primer contenido falso relacionado con el coronavirus, hasta el 25 de mayo de 2020, fecha desde la cual ningún territorio español se encontraba ya en la llamada fase 0, sino que todo el país había iniciado el proceso de desescalada, encontrándose algunas provincias en fase 1 y otras en fase 2. Todas las verificaciones objeto de estudio fueron publicadas en la Zona de Verificación (Fakes) de newtral.es.

El estudio incluye todos aquellos contenidos verificados por Newtral durante la crisis de la Covid-19, relacionados de alguna manera con la pandemia, no sólo referentes a cuestiones sanitarias, sino también sobre otras cuestiones vinculadas a la situación generada por el coronavirus y sus consecuencias, como el confinamiento o las medidas políticas adoptadas en esos días. No se han incluido en la muestra aquellos contenidos falsos difundidos durante el período de estudio que no guardan relación con la Covid-19.

Los 205 contenidos analizados fueron detectados por el propio equipo de fact-checkers de Newtral o bien recibidos a través de su servicio de "verificación bajo demanda" vía WhatsApp, un canal que la empresa ofrece al público para que a través de esta plataforma de mensajes privada cualquier persona pueda dirigirse a Newtral para consultar si determinada información es real o es falsa.

2. En el análisis de la muestra se han estudiado en primer lugar los procedimientos de verificación. Para ello se han considerado las especificaciones detalladas por Newtral en cada una de sus verificaciones. Conforme al Código de Principios de la ifcn antes mencionado, éstas deben ser transparentes en cuanto a la metodología empleada y las fuentes consultadas. En este sentido, se ha partido de una tipología que incluye: consulta a diversos tipos de fuentes, a otros medios de comunicación y fact-checkers, o bien la utilización de diversas 
herramientas informáticas de verificación como InVId, TinEye, Google Imágenes o Yandex, entre otras.

En el caso de que para la verificación se haya recurrido a fuentes, éstas se especifican en la propia verificación y hemos procedido a su catalogación diferenciando entre: fuentes expertas, oficiales, documentales (en la mayoría de los casos consulta en el BOE de reales decretos que fueron aprobándose y publicándose durante la crisis), fuentes originales de la imagen manipulada o sacada de contexto, fuentes suplantadas (en el caso de contenido impostor), o bien fuentes citadas o afectadas.

3. De cada uno de los 205 contenidos verificados analizados se ha recogido la siguiente información:

- -Título de la noticia de la verificación publicada en newtral.es.

- Enlace a la verificación en la web.

- -Fecha de verificación. Se especifica la fecha de la publicación del contenido analizado o, en la mayoría de los casos, la de la publicación de la verificación, generalmente pocos días después de su detección.

- -Formato: texto, video, mensaje de audio, imagen, supuesto documento, supuesta noticia y mensaje de correo electrónico.

- $\quad$-Red en la que fue detectado el contenido. Se recoge si es Facebook, Twitter, Instagram o WhatsApp. Aunque WhatsApp es una aplicación de mensajería privada, no una red social, se ha incluido bajo este epígrafe de "redes" ya que ha jugado un papel igual de importante en la difusión de contenidos falsos.

- -Origen del contenido falso.

- -Tipos de contenidos falsos. Para catalogar los bulos se ha seguido la tipología de Wardle publicada en la web de First Draft (2017), ordenados de menos a más dañinos en función de su intención de engañar. De manera que se ha distinguido entre: sátira o parodia, conexión falsa (titulares o imágenes que no se corresponden con el contenido de la información), contenido engañoso, contexto falso, contenido impostor (fuente suplantada), contenido manipulado y contenido fabricado. También se ha considerado una categoría no contemplada por Wardle, pero detectada en esta crisis de desinformación de la Covid-19, consistente en que la supuesta información mezcla contenidos falsos y verdaderos.

- -Posibles riesgos que entraña el contenido difundido, distinguiendo entre cuatro: desinformar, generar alarma, provocar rechazo o perjuicio (a una persona, colectivo o país) y fraude o estafa.

4. Con el fin de contrastar los datos considerados en el estudio y de conocer la percepción del propio equipo de fact-checkers de Newtral, se ha cotejado la información obtenida a través de la observación y análisis con una entrevista personal no estructurada a Joaquín Ortega, director de contenidos de la organización. Con ello se ha buscado controlar el sesgo personal de los investigadores y cubrir posibles deficiencias, buscando incrementar la validez del estudio al tiempo que ha permitido obtener datos necesarios para conocer el objeto de estudio.

\section{Resultados}

\subsection{Métodos de verificación empleados por Newtral}

Tras hacer el seguimiento de las especificaciones detalladas por Newtral en cada una de sus verificaciones, de acuerdo con la política de transparencia en la metodología que establece el Código de Principios de la IFCN, se observa que el método de verificación empleado por su equipo de factcheckers se ha basado en la utilización de distintos tipos de fuentes y de diversas herramientas 
tecnológicas. En fuentes se ha incluido la consulta o colaboración con otros equipos de fact-checkers miembros de la IFCN y con otros medios de comunicación.

En la mayoría de los casos se utiliza más de un método de verificación, y cuando se emplea un mismo método, es frecuente que se utilice más de una fuente y de distinto tipo, o bien diferentes herramientas de verificación. Se han llegado a contabilizar hasta ocho fuentes y /o herramientas distintas utilizadas en una misma verificación.

En la muestra estudiada es mucho más frecuente la consulta a fuentes (90,5\% de los casos), que el empleo de herramientas tecnológicas $(9,5 \%)$. El director de contenidos de Newtral, Joaquín Ortega, lo confirma así: "Quizá el método de verificación que más hemos empleado en esta pandemia ha sido el menos tecnológico de todos, el de consultar por teléfono o por mail con expertos de virología, epidemiología, medicina... Muchos de estos contenidos a verificar incluían bulos sobre falsos remedios o descubrimientos científicos que no eran tales. En nuestra metodología nos exigimos consultar con varios expertos reconocidos de institutos o unidades solventes para tener la absoluta certeza de que lo que estamos comprobando es falso o no. En temas de verificación de salud hay que tenerlo todo muy atado, ser claros y directos a la hora de explicarlo".

El estudio revela que las fuentes más consultadas son las oficiales, a las que con frecuencia se solicitan datos. Entre las más contactadas destacan el Ministerio de Sanidad, la OMS, la Policía Nacional, Guardia Civil y policías autonómicas. En segundo lugar, aparecen las fuentes suplantadas, seguidas por las fuentes citadas o aludidas en el contenido falso. A continuación, se recurre a otros fact-checkers miembros de la IFCN como Alt News (India), Chequeado (Argentina), Ecuador Chequea, Full Fact (Reino Unido), Snopes, AfricaCheck, AFP Factual o Les Décodeurs (Le Monde).

Las siguientes fuentes más consultadas son las fuentes originales, que pueden ser el video original sobre el que se informa, las declaraciones originales de un personaje público o la web de la que parte la información y que resulta ser una web satírica, por ejemplo. Por último, y en este orden, se recurre a fuentes documentales (textos legales en casi todos los casos), fuentes expertas (generalmente vinculadas a distintas universidades) y medios de comunicación, en su mayoría internacionales (fundamentalmente de China) o locales.

En cuanto a las herramientas empleadas en las verificaciones estudiadas, en el caso de la crisis del coronavirus éstas no han necesitado ser muy sofisticadas ni tecnológicas. Todas ellas son aplicaciones gratuitas disponibles en Internet. "Una de las herramientas que más usamos es la búsqueda de contenidos ya publicados y almacenados en plataformas como Google, Yandex, Bing o TinEye. ¿Por qué? Porque la gente que se dedica a producir fakes normalmente utiliza elementos disponibles en la red. Fotos de personas, situaciones, edificios, videos en redes, etc que ya existen, y que se manipulan con herramientas de edición audiovisual o situando lo que ocurre en sitios que no son o implicando a personas que nunca estuvieron allí”, señala Ortega.

Las más utilizadas son motores de búsqueda como Google Imágenes o Yandex, que permiten el rastreo de imágenes en Internet realizando una búsqueda inversa para encontrar imágenes similares a la que se quiere verificar y comprobar así si es anterior a lo que asegura la información falsa, ya que utilizar imágenes antiguas como si fueran actuales es una práctica muy habitual.

En segundo lugar, se recurre a InVId, una herramienta específica para verificar videos. Esta herramienta de la agencia francesa de noticias AFP proporciona datos básicos sobre la publicación, producción, derechos y el emisor de un video. Permite además realizar búsquedas inversas de fotogramas de un vídeo. 
En tercero, se utilizan herramientas de geolocalización -como Google Maps, Google Earth o Baidu Maps- que sirven para comprobar si un hecho ocurrió realmente en un lugar. A continuación, el método más utilizado es el que se ha denominado análisis del contenido y en el que se han incluido algunas prácticas sencillas de verificación como comprobar la cuenta de origen de un tuit o analizar un video para observar que no es España, por ejemplo.

La siguiente herramienta utilizada es TinEye, una web que permite averiguar cuándo fue la primera vez que se subió una imagen a Internet, un dato clave en la verificación de los montajes que sitúan una fotografía en una fecha falsa.

Tabla 1. Métodos de verificación empleados por Newtral

\begin{tabular}{|l|l|l|l|}
\hline FUENTES & $\mathbf{2 8 6}(\mathbf{9 0 , 5 \% )}$ & HERRAMIENTAS & $\mathbf{3 0}(\mathbf{9 , 5 \% )}$ \\
\hline Fuente oficial & 102 & Motor de búsqueda & 13 \\
\hline Fuente suplantada & 42 & InVid & 6 \\
\hline Fuente citada & 40 & Geolocalización & 5 \\
\hline Otros fact-checkers & 27 & Análisis del contenido & 3 \\
\hline Fuente original & 21 & TinEye & 2 \\
\hline Fuente documental & 20 & Otras & 1 \\
\hline Fuente experta & 19 & & \\
\hline Medios de comunicación & 13 & & \\
\hline
\end{tabular}

Fuente: elaboración propia a partir de información de newtral.es

\subsection{Evolución temporal de las verificaciones realizadas por Newtral}

El primer bulo relacionado con el coronavirus detectado por el equipo de Newtral fue localizado en Facebook, el 25 de enero de 2020, y verificado el 28 de enero. Se trataba de un vídeo, compartido más de 2.000 veces, y decía mostrar imágenes del mercado de Wuhan (foco del brote del coronavirus en China), pero en realidad estaba grabado en Indonesia. Verificado a través de la herramienta InVid, se comprobó que las mismas imágenes habían sido subidas en junio de 2019 a YouTube.

Desde este primer bulo relacionado con la Covid-19, hasta el principio de la desescalada para toda España el 25 de mayo, cuando los territorios que aún permanecían en fase 0 pasaron a la fase 1 y algunos a la 2, se registraron un total de 205 contenidos verificados por Newtral, lo que supone una media de 1,7 contenidos verificados al día.

Este análisis cronológico sirve para observar la evolución de la infodemia. Las fechas registradas son en su gran mayoría las de la publicación de la verificación, que suele ser uno o dos días después de su detección en redes. Solo en algún caso excepcional se ha verificado un bulo que se detectó por primera vez meses antes, como el que se publica bajo el título "El bicho extraído de un labio en un video viral no vive en latas de refrescos ni es efecto del coronavirus", que se verifica en febrero de 2020, pero se detectó por primera vez en octubre de 2019.

Entre el 25 de enero y el 9 de marzo (cinco días antes de que se decretase el estado de alarma) es cuando menos contenidos falsos se detectan y se verifican. Durante ese primer periodo, los contenidos verificados al día oscilan entre 0 y 4, registrándose un 0,7 de media. El 10 de marzo se produce un punto de inflexión al dispararse el número de contenidos verificados hasta 10. A partir del día siguiente (11 de marzo), los contenidos verificados oscilan entre 0 y 6 al día, siendo la media de ese segundo periodo sensiblemente más alta que la del primero, con 2,3 contenidos verificados al día. 
RLCS, Revista Latina de Comunicación Social, 78, 289-308

[Investigación] DOI: 10.4185/RLCS-2020-1478| ISSN 1138-5820| Año 2020

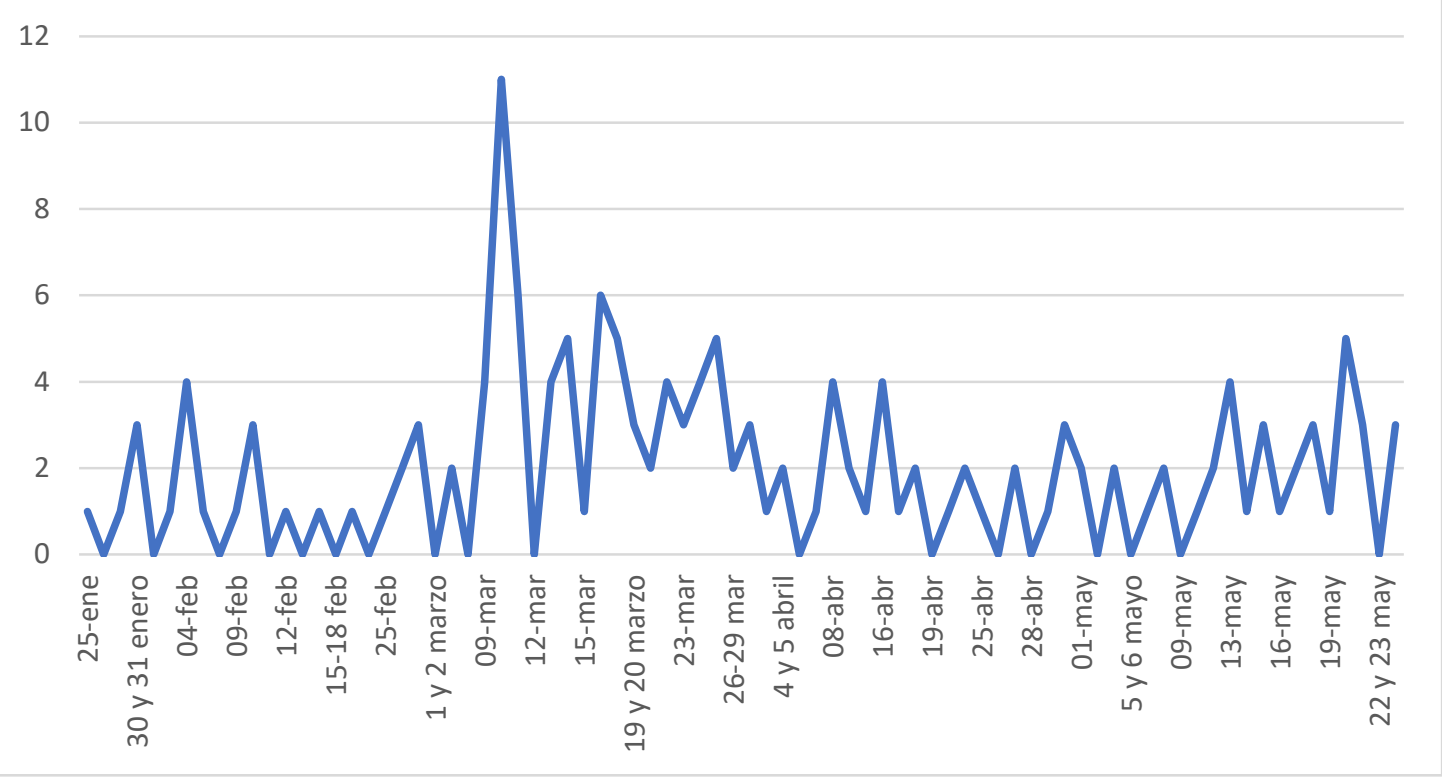

Gráfico 1. Número de contenidos falsos verificados al día por Newtral Fuente: elaboración propia a partir de datos de newtral.es

\subsection{Formato de los contenidos falsos}

En cuanto a los formatos de los contenidos verificados, el más difundido es el de los mensajes de texto compartidos en redes sociales (publicaciones de Facebook, stories de Instagram y tuits) o a través de una cadena de WhatsApp. No se citan fuentes y pueden incluir todo tipo de contenidos: falsos remedios contra el coronavirus, informaciones falsas sobre medidas políticas tomadas, etc.

El segundo formato más utilizado es el vídeo, seguido de la foto o captura de una imagen. En tercer lugar, se sitúan los documentos falsos, como una supuesta carta o comunicado de un organismo oficial. En este sentido, se han detectado, por ejemplo, falsos comunicados del Ayuntamiento de Barcelona, la Universidad de Sevilla, la Xunta de Galicia, el Ministerio de Educación y Unicef, entre otros. En cuarto, las supuestas noticias de un medio de comunicación reconocido, como $L a$ Vanguardia, la Cadena SER o la Agencia EFE, por ejemplo. Los falsos tuits de medios de comunicación se han incluido en esta categoría de supuestas noticias ya que pretenden lograr el mismo efecto.

El quinto formato más utilizado son los mensajes de audio. El director de contenidos de Newtral destaca el incremento de este formato: "los mensajes de audio ya se usaban para diseminar alertas falsas o relatos inventados, pero durante la pandemia se han multiplicado". Por último, y bastante menos frecuentes, aparecen los mensajes de correo electrónico.

Tabla 2. Formatos de los contenidos verificados por Newtral

\begin{tabular}{|l|c|c|}
\hline \multicolumn{1}{|c|}{ FORMATO } & $\mathbf{N}^{\mathbf{0}}$ contenidos & \% \\
\hline Texto & 85 & 41,4 \\
\hline Vídeo & 42 & 20,4 \\
\hline Imagen & 28 & 13,6 \\
\hline Supuesto documento & 18 & 8,7 \\
\hline Supuesta noticia & 15 & 7,4 \\
\hline Audio & 13 & 6,4 \\
\hline Correo electrónico & 4 & 2,0 \\
\hline
\end{tabular}

Fuente: elaboración propia a partir de datos de newtral.es

Nota: En un caso un mismo contenido se ha presentado en dos formatos diferentes. Ambos han sido contabilizados. 


\subsection{Canal de difusión}

Por lo que respecta a la difusión de los contenidos falsos, la mayoría (un 66\%) se detectaron en más de una red, incluyendo la red de mensajería WhatsApp. En cuanto a los contenidos difundidos sólo por un canal, la mayoría se viralizó a través de WhatsApp, seguido de las redes sociales Twitter y Facebook, en este orden. En la muestra también se detectan cuatro contenidos que se difundieron vía correo electrónico o mensajes SMS, todos ellos casos de estafas. Por último, dos videos falsos o manipulados se distribuyeron también a través de TV.

Tabla 3. Canal a través del cual se distribuyó el contenido falso

\begin{tabular}{|l|l|}
\hline CANAL & $\mathbf{N}^{\mathbf{0}}$ contenidos \\
\hline Varias redes & 136 \\
\hline WhatsApp & 36 \\
\hline Twitter & 18 \\
\hline Facebook & 8 \\
\hline Correo electrónico y SMS & 4 \\
\hline Otros / TV & 2 \\
\hline Medio digital & 1 \\
\hline
\end{tabular}

Fuente: elaboración propia a partir de datos de newtral.es

\subsection{Origen de los contenidos verificados}

En el 91,7\% de los contenidos verificados resulta imposible detectar el origen, es decir, localizar de dónde parte el contenido o quién generó éste por primera vez. En esos casos el origen se clasifica como "desconocido". Tan sólo cuando el contenido ha partido de un usuario determinado de una red social como Twitter o Facebook se ha podido identificar la cuenta.

Sí se ha detectado cuando el origen es un medio digital, del que luego se han hecho eco otros portales digitales y distintos mensajes en redes sociales, viralizando el contenido. Asimismo, en un caso se ha podido concluir que el origen estaba en otro país diferente a España (Francia), pero sin poder concretar más. Solo en una ocasión ha sido posible identificar a la persona que difunde el contenido, que en este caso mezcla información correcta e incorrecta sin voluntad de desinformar. Por último, en algunos casos no es posible detectar el origen pero sí a alguna de las personas que contribuyeron a viralizar el bulo, como es el caso en el que el diputado del PP, Rafael Hernando, se hizo eco de una supuesta imagen de un grupo de musulmanes en la calle durante el confinamiento que en realidad era de 2018, y posteriormente rectificó en la misma red social.

Tabla 4. Origen de los contenidos verificados

\begin{tabular}{|l|l|}
\hline ORIGEN & $\mathbf{N}^{\mathbf{0}}$ contenidos \\
\hline Desconocido & 188 \\
\hline Cuenta de Twitter & 10 \\
\hline Cuenta de Facebook & 1 \\
\hline Cuenta de TikTok & 1 \\
\hline Medio digital & 2 \\
\hline Web satírica & 1 \\
\hline Persona identificada & 1 \\
\hline Dirección correo electrónico & 1 \\
\hline
\end{tabular}

Fuente: elaboración propia a partir de datos de newtral.es 


\subsection{Tipología de los contenidos}

Se ha observado que los contenidos más frecuentes son precisamente los más dañinos, según la clasificación de Wardle (2017), los denominados contenidos fabricados. Un ejemplo es el que se difundió a través de Facebook y Twitter y se verificó el 29 de enero bajo el título "Es falso que haya informes sobre más de 10.000 muertos en Wuhan a causa del coronavirus". En segundo lugar, aparecen los contenidos impostores, que suplantan a una fuente, como en el caso de un supuesto documento del Ministerio de Sanidad difundido el 9 de febrero que recomendaba "no suministrar productos provenientes de China" y que en realidad se trataba de una falsificación. En tercero, se encuentran aquellos contenidos que falsifican el contexto (contexto falso), como un vídeo de un caimán supuestamente grabado en Getxo (Vizcaya) y relacionado con los cambios en la naturaleza provocados por el coronavirus. El video en realidad se grabó en 2015 en el estado de Alabama (Estados Unidos).

El 24 de mayo se detecta un caso curioso, ya que se acusa a una información verdadera de ser un contenido de contexto falso. En este caso la verificación consiste precisamente en demostrar que el video aludido sí se sitúa en el contexto citado (una ambulancia que intenta atravesar una manifestación de Vox el 23 de mayo de 2020 en Santander).

Por último, el análisis realizado detecta muy pocos contenidos satíricos y de conexión falsa. Además, se observan cinco casos que no entran en ninguna de las otras siete tipologías, al mezclar información correcta e incorrecta, y no quedar claro que haya ningún tipo de motivación detrás.

Tabla 5. Tipología de los contenidos verificados ordenados de menos a más dañino

\begin{tabular}{|l|c|c|}
\hline \multicolumn{1}{|c|}{ TIPO DE CONTENIDO } & $\mathbf{N}^{\mathbf{0}}$ contenidos & \% \\
\hline Mezcla contenido falso y verdadero & 5 & 2,4 \\
\hline Sátira o parodia & 4 & 2,0 \\
\hline Conexión falsa & 3 & 1,5 \\
\hline Contenido engañoso & 17 & 8,3 \\
\hline Contexto falso & 47 & 22,9 \\
\hline Contenido impostor & 48 & 23,4 \\
\hline Contenido manipulado & 12 & 5,9 \\
\hline Contenido fabricado & 69 & 33,6 \\
\hline
\end{tabular}

Fuente: elaboración propia.

Dentro de los contenidos de carácter impostor, se ha realizado un análisis de las fuentes suplantadas, siendo las más frecuentes los medios de comunicación. Se han detectado suplantaciones de El País, El Mundo, La Vanguardia, La Razón, RTVE, Agencia EFE, Cadena SER, La Voz de Galicia, Público, eldiario.es y de su director, Ignacio Escolar.

En segundo lugar, las fuentes más suplantadas son las agrupadas bajo el nombre de "Empresas y organismos" -que incluyen a empresas como Netflix, Caixabank, Leroy Merlín y Carrefour, así como a organismos como Cáritas, Correos, la Seguridad Social y la Agencia Tributaria-. En estos casos existe el riesgo de que se cometa un fraude o estafa.

En tercer lugar, se sitúan las fuentes de Presidencia del Gobierno y de tres ministerios (Sanidad, Interior y Educación), seguido de varias fuentes autonómicas de Madrid, Galicia, Cataluña y Comunidad Valenciana. También fueron suplantadas cuatro universidades (Universidad de Sevilla, Universidad de Jaén, Stanford University y Universidad de Barcelona), organismos oficiales como la OMS, Unicef y la ONU, ayuntamientos (Barcelona, Málaga y Tarragona), autoridades sanitarias extranjeras, Policía y Guardia Civil, y fuentes sanitarias españolas, en concreto, el Jefe de Cardiología del Hospital Gregorio Marañón. 
RLCS, Revista Latina de Comunicación Social, 78, 289-308

[Investigación] DOI: 10.4185/RLCS-2020-1478| ISSN 1138-5820| Año 2020

Tabla 6. Fuentes suplantadas en los contenidos de tipo impostor

\begin{tabular}{|l|l|}
\hline FUENTE SUPLANTADA & $\mathrm{N}^{\mathrm{o}}$ contenidos \\
\hline Medios de comunicación & 13 \\
\hline Empresas y organismos & 8 \\
\hline Gobierno & 7 \\
\hline CCAA & 6 \\
\hline Universidades & 4 \\
\hline Organismos oficiales internacionales & 3 \\
\hline Ayuntamientos & 3 \\
\hline Autoridades sanitarias extranjeras & 2 \\
\hline Policía y Guardia Civil & 2 \\
\hline Autoridad sanitaria española & 1 \\
\hline
\end{tabular}

Fuente: elaboración propia.

Se han detectado varios casos en los que el mismo contenido falso se difunde en varios lugares diferentes, como unas imágenes de bolsas de cadáveres en el suelo que eran de Ecuador y se distribuyeron en varios países como si hubieran sido grabados en hospitales locales de Estados Unidos y España (en Madrid y Barcelona).

En otros casos lo que cambia es el formato del contenido y la comunidad autónoma a la que se refiere, como en la supuesta noticia difundida en Cataluña y Madrid (en forma de mensaje de audio y de supuesto documento, respectivamente) sobre una banda de ladrones disfrazados de médicos que habrían entrado en domicilios con la excusa de realizar tests del coronavirus pero con la intención de robar.

Por otro lado, se ha observado que algunos contenidos falsos se han difundido en varios momentos diferentes a lo largo de la crisis por la pandemia. Por ejemplo, unas supuestas reglas que debían cumplirse durante el estado de alarma fueron difundidas a mediados de marzo y volvieron a viralizarse a mediados de abril.

\subsection{Riesgos que comportan los contenidos falsos verificados}

En cuanto a los posibles riesgos que entrañan los contenidos verificados, la mera desinformación aparece en 113 ocasiones (el 55,1\% de la muestra). En el caso de la Covid-19 muchos bulos de este tipo suponen además un riesgo para la salud porque recomiendan supuestos tratamientos contra el virus que pueden ser nocivos. Tal es el caso de un mensaje compartido por WhatsApp y verificado el 10 de marzo que aseguraba que contener la respiración permitía saber si alguien estaba infectado por coronavirus. Este tipo de mensajes se han detectado en 14 ocasiones.

Generar alarma es el segundo riesgo más frecuente, al observarse en 45 casos (21,9\% del total). Un ejemplo es el mensaje que circuló por redes y fue verificado el 16 de marzo que aseguraba que durante el estado de alarma decretado por el coronavirus las aseguradoras dejaban de cubrir los accidentes de tráfico. El tercero, que se detecta en 37 ocasiones $(18,0 \%)$, es provocar un rechazo o perjuicio hacia una persona, institución o colectivo, como una supuesta noticia que alertaba de que un grupo de vecinos gitanos de Haro habían rechazado seguir los protocolos de Sanidad.

Por último, en el cuarto (10 casos detectados, un 4,8\%) puede haber fraude o estafa, como el mensaje que circuló por la red a principios de abril que indicaba que Cáritas ofrecía cupones diarios de hasta 1.000 euros a cualquier persona que lo solicitara rellenando una solicitud con datos personales y el número de cuenta bancaria. No se registra ningún contenido de este tipo antes del 23 de marzo y la mayoría son casos de phishing, una práctica que busca obtener de manera ilegal datos personales de alguien. 
En los casos en que existe más de un riesgo se ha contabilizado el considerado principal.

Dentro del apartado "rechazo o perjuicio" se ha analizado a quién pueden perjudicar los contenidos falsos. En este sentido, se observa que aquellos con riesgo de perjudicar a un político son los más numerosos. Se han detectado contenidos potencialmente perjudiciales para políticos españoles como Manuela Carmena, Irene Montero, Pablo Iglesias, Teresa Rodríguez, Pablo Casado, Santiago Abascal y José María Aznar; extranjeros como Christine Lagarde y Vladimir Putin, y para partidos políticos (Podemos) y la clase política en general. Todos ellos se han detectado a partir del 10 de marzo.

En segundo lugar, se sitúan los contenidos que entrañan riesgo de perjudicar al Gobierno en su totalidad o a alguno de sus miembros, fundamentalmente al presidente. $\mathrm{Y}$ en tercero, aquellos que podrían dañar la imagen de un determinado colectivo (se han detectado contenidos contra gitanos, musulmanes, personas transgénero y manifestantes contra el Gobierno) o un país (todos los que aparecen en la muestra se refieren a China). Por último, se ha detectado un contenido contrario al rey y otro referente a un periodista.

Tabla 7. Contenidos con riesgo de generar rechazo o perjuicio a determinados colectivos

\begin{tabular}{|l|l|}
\hline COLECTIVO & $\mathbf{N}^{\mathbf{0}}$ contenidos \\
\hline Políticos & 14 \\
\hline Gobierno & 12 \\
\hline Colectivos & 5 \\
\hline País & 4 \\
\hline Rey & 1 \\
\hline Periodista & 1 \\
\hline
\end{tabular}

Fuente: elaboración propia.

\section{Discusión}

Partiendo de los resultados de la investigación una vez analizados los 205 contenidos falsos verificados por Newtral entre el 25 de enero y el 25 de mayo de 2020, y teniendo en cuenta las preguntas de partida de la investigación, se observa cómo Newtral ha empleado una amplia diversidad de métodos de verificación, si bien se constata que se recurre mayoritariamente a fuentes de consulta para el contraste de los contenidos frente al escaso uso de herramientas tecnológicas. Dicho resultado lleva a plantear la importancia de los métodos periodísticos tradicionales en los procesos de verificación, más allá del soporte complementario que puedan suponer en este sentido nuevas herramientas como los motores de búsqueda u otras más sofisticadas.

$\mathrm{Al}$ observar las fuentes consultadas en las verificaciones es llamativo que, tras las fuentes oficiales, en segundo lugar se acude a las fuentes suplantadas. Ello es aún más relevante si se tiene en cuenta que los contenidos impostores (aquellos que suplantan fuentes) son los segundos más detectados en la muestra analizada. Entre las fuentes más suplantadas identificadas en el epígrafe de resultados, destacan diversos medios de comunicación, empresas, organismos oficiales y gubernamentales. Esta situación lleva a plantearse la necesidad de que estos actores tengan la previsión de contar con equipos expertos en la detección y verificación de contenidos falsos difundidos por las redes.

En cuanto a la evolución temporal de los contenidos verificados, se observa un incremento a partir del 9 de marzo, si bien la evolución no es constante. Resulta significativo cómo el mayor aumento de verificaciones a lo largo del periodo analizado (cuatro meses) se produce entre el 9 y el 12 de marzo. 
Teniendo en cuenta que las fechas registradas en el gráfico 1 corresponden en su mayoría a las de publicación de la verificación y que ésta suele ser de uno o dos días después de su detección en redes, se interpreta que el pico de difusión de contenidos falsos se corresponde con los días posteriores al 8 de marzo, coincidiendo con las polémicas generadas en torno a las manifestaciones celebradas en dicha fecha y con la declaración de pandemia por parte de la OMS. Resulta llamativo que el mayor número de contenidos falsos detectados correspondiera a estas fechas anteriores a la declaración del estado de alarma en España.

Por lo que respecta a los canales utilizados para la difusión de los contenidos falsos, es interesante señalar que en la mayoría de los casos se produce a través de más de una red social, aunque el canal prioritario es la red de mensajería privada WhatsApp, sistema de comunicación especialmente utilizado en España.

$\mathrm{Al}$ analizar los datos se han percibido limitaciones a la hora de detectar el origen de los contenidos analizados. Ello es consecuencia, en algunas ocasiones, de que la información parte de cuentas anónimas, lo que supone un campo de estudio que merece el interés desde perspectivas diversas, tanto informativas como tecnológicas y legales.

En lo que se refiere a los riesgos que entrañan los contenidos falsos difundidos, en este caso, al tratarse de una crisis sanitaria de gran magnitud, la mera desinformación implica en muchos casos un riesgo para la salud de quien recibe el contenido, por lo que resulta especialmente peligrosa su viralización.

\section{Conclusiones}

Tal y como afirma Cebrián-Enrique (2012) la diversidad y complejidad de la realidad periodística impide el establecimiento de un método universal de verificación. Ello se hace evidente en el caso de Newtral durante el periodo analizado, donde se observa la utilización de diferentes sistemas y herramientas de verificación, si bien se aprecia un predominio de unos sobre otros. Así pues, se constata cómo la consulta a diversas fuentes es el método más utilizado durante la crisis de la Covid19, especialmente fuentes oficiales y las que han sido suplantadas. Resulta llamativo cómo se recurre más al uso de fuentes que al de herramientas de verificación, que además se caracterizan por ser muy básicas, siendo las más utilizadas los motores de búsqueda como Google Imágenes o Yandex.

En lo que se refiere a los contenidos falsos detectados se observa cómo su número alcanza el máximo de verificaciones el 10 de marzo, cuatro días antes de decretarse el estado de alarma por el Gobierno, y se mantiene más alto durante todo ese segundo periodo analizado, en el que España se encuentra en situación de confinamiento y en plena crisis sanitaria. Al mismo tiempo, en consonancia con estudios previos, como el de Cinelli et al. (2020) y MacNair (2018), se ha constatado el papel de las redes sociales en la difusión de los contenidos verificados por Newtral, observándose un predominio de mensajes de texto difundidos en redes sociales o a través de una cadena de mensajería privada como WhatsApp. Se ha detectado, asimismo, que la generalidad de los contenidos se difundió a través de más de una red, si bien en la mayoría de los casos no se pudo identificar el origen.

En cuanto a la tipología de los contenidos verificados, los más difundidos fueron los contenidos fabricados, considerados por autores como Wardle (2017) los más dañinos, seguidos de los contenidos impostores que suplantan a una fuente (fundamentalmente medios de comunicación, empresas y organismos en el caso de las estafas, y fuentes del gobierno central y autonómicos) y de aquellos que falsifican el contexto. En este último tipo y en el caso de los videos, éstos con frecuencia se viralizaron de forma global. Precisamente, esta tipología de contenidos, unida a la 
rápida difusión a través de redes sociales, tal y como ya alertaban en estudios previos autores como Ortiz de Guinea y Martín-Sáez (2019) o Silverman (2014), han propiciado una vez más que la desinformación sea el riesgo más frecuente, seguida en este caso de la posibilidad de generar alarma y provocar un rechazo o perjuicio hacia una persona, colectivo o institución.

Igualmente se ha observado que la tipología de contenidos no es similar a lo largo de todo el periodo analizado. En este sentido, se ha constatado que algunos contenidos, como los que entrañan perjuicio para los políticos o implican fraude o estafa, no se difundieron durante las primeras semanas y solo aparecieron desde mediados del mes de marzo, cuando ya se vislumbraba la magnitud de la crisis.

Los riesgos de desinformación que comportan este tipo de crisis, como la de la Covid-19, provocan que no solo los equipos de fact-checkers realicen labores de verificación, sino que diversas fuentes se habrían visto obligadas a emitir desmentidos que se realizan habitualmente a través de las mismas redes por la que se difunde el contenido falso. En este sentido, parece razonable concluir que los departamentos de comunicación de organismos oficiales y empresas privadas de gran tamaño irán incorporando perfiles profesionales expertos en verificación a sus equipos para poder hacer frente a este tipo de infodemias, abriéndose un ámbito de actuación que resulta de interés para futuras investigaciones en comunicación.

\section{Bibliografía}

Aldama, Z. (2020, enero 5). Un brote de neumonía atípica en China revive el fantasma de la epidemia mortal". Heraldo de Aragón. https://www.heraldo.es/noticias/internacional/2020/01/05/un-brote-de-neumonia-atipica-en-chinarevive-el-fantasma-de-la-epidemia-mortal-1351994.html

Allcott, H. y Gentzkow, M. (2017). Social Media and Fake News in the 2016 Election. Journal of Economic Perspectives, 31 (2), 2011-2036. https://doi.org/10.1257/jep.31.2.211

Amorós-García, M. (2019). Los medios de comunicación contra las noticias falsas: todo es falso, ¿salvo el periodismo? Cuadernos de Periodistas, (38), 21-40.

Aparici, R., García-Marín, D. y Rincón-Manzano, L. (2019). Noticias falsas, bulos y trending topics. Anatomía y estrategias de la desinformación en el conflicto catalán. El profesional de la Información, 28 (3).https://doi.org/10.3145/epi.2019.may.13

Bernal-Triviño, A. y Clares-Gavilán, J. (2019). Uso del móvil y las redes sociales como canales de verificación de Fake News. El caso de Maldita.es. El profesional de la información, 28 (3), 1-8. https://doi.org/10.3145/epi.2019.may.12

Blanco-Alfonso, I., García Galera, C. y Tejedor Calvo, S. (2019). El impacto de las fake news en la investigación en Ciencias Sociales. Revisión bibliográfica sistematizada. Historia y comunicación social, 24 (2), 449-469. https://doi.org/10.5209/hics.66290

Blanco-Alfonso, I. (2020). Posverdad, percepción de la realidad y opinión pública. Una aproximación desde la fenomenología. Revista de Estudios Políticos, (187), 167-186. https://doi.org/10.18042/cep/rep.187.06

Blanco-Herrero, D. y Arcilla-Calderón, C. (2019). Deontología y noticias falsas: estudio de las percepciones de periodistas españoles”. El profesional de la información, 28 (3), 1-

13.https://doi.org/10.3145/epi.2019.may.08 
RLCS, Revista Latina de Comunicación Social, 78, 289-308

[Investigación] DOI: 10.4185/RLCS-2020-1478| ISSN 1138-5820| Año 2020

Blázquez-Ochando, M. (2018). El problema de las noticias falsas: detección y contramedidas. En: XV Seminario Hispano-Mexicano de Investigación en Biblioteconomía y Documentación, Ciudad de México.

Boyd, D. (2017, marzo 27). Google and Facebook can't just make Fake News Disappear. En Wired. https://www.wired.com/2017/03/google-and-facebook-cant-just-make-fake-news-disappearl

Brennen, S., Simon, F., Howard, Ph. y Nielsen, R. (2020, abril 7). Types, sources and claims of COVID-19 misinformation. https://reutersinstitute.politics.ox.ac.uk/types-sources-and-claimscovid-19-misinformation

Cinelli, M., Quattrociocchi, W., Galeazzi, C., Brugnoli, E., Schimidt, A; Zola, P., Zollo, F. y Scala, A. (2020). The COVID-19 Social Media Infodemic. arXiv:2003.05004vl [cs.SI]. Cornell University, 1-18. https://arxiv.org/pdf/2003.05004v1.pdf

Casero-Ripollés, A. (2020). Impacto del Covid-19 en el sistema de medios. Consecuencias comunicativas y democráticas del consumo de noticias durante el brote. El Profesional de la información, 29 (2), 1-12. https://doi.org/10.3145/epi.2020.mar.23

Cebrián-Enrique, B. (2012). Al rescate de la verificación periodística. Zer, 17 (33), 227-241. https://ojs.ehu.eus/index.php/Zer/article/view/10633

Coromina, Ó., Prado, E. y Padilla, A. (2018). The grammatization of emotions on Facebook in the elections to the Parliament of Catalonia 2017. El profesional de la información, 27 (5), 10041011. https://doi.org//10.3145/epi.2018.sep.05

De la Cal, L. (2020, enero 8). La misteriosa neumonía que está poniendo nerviosa a China. El Mundo.https://www.elmundo.es/cienciasalud/salud/2020/01/08/5e146e4121efa044108b4631.html

Elías, C. (2018). Fakenews, poder y periodismo en la era de la posverdad y 'hechos alternativos'. Ámbitos. Revista Internacional de comunicación (40), 1-6. https://revistascientificas.us.es/index.php/Ambitos/article/view/8913

Fernández-García, N. (2017). Fake News: una oportunidad para la alfabetización mediática. Nueva Sociedad, (269), 66-77.

Guess, A., Nagler, J. y Tucker, J. (2019). Less than you think: Prevalence and predictors of fake news dissemination on Facebook. Science Advances, 5 (1).

https://doi.org/10.1126/sciadv.aau4586

Jack, C. (2017). Lexicon of Lies. Data \& Society. https://datasociety.net/pubs/oh/DataAndSociety_LexiconofLies.pdf

Jiménez-Cruz, C. (2019). En la era de la desinformación, periodismo para que no te la cuelen. Cuadernos de Periodistas, (38), 13-20. http://www.cuadernosdeperiodistas.com/en-la-era-de-ladesinformacion-periodismo-para-que-no-te-la-cuelen/

Jurado-Salván, E. y Jurado-Izquierdo, M. (2014). Los errores de comunicación en la crisis del Ébola. Cuadernos de Periodistas, (29), 90-99. http://www.cuadernosdeperiodistas.com/los-errores-decomunicacion-en-la-crisis-del-ebola/ 
Magallón-Rosa, R. (2018a). Leyes fake news. El problema para la libertad de información de no legislar. Telos, https://telos.fundaciontelefonica.com/las-leyes-las-fake-news-problema-lalibertad-informacion-no-legislarl

Magallón-Rosa, R. (2018b). Nuevos formatos de verificación El caso de Maldito Bulo en Twitter. Sphera Pública, 1 (18), 41-65. http://sphera.ucam.edu/index.php/sphera-01/article/view/341

Marcos-Recio, J.C. (2017). Verificar para mejorar la información en los medios de comunicación con fuentes documentales. Hipertext.net: Revista académica sobre documentación digital y comunicación interactiva, (15), 36-45. https://doi.org/10.2436/20.8050.01.44

Martín-Barato, A.; López-Doblas, M.; Luque-Martín, N. y March-Cerdá, J. C. (2020, abril 15). Fake news y bulos contra la seguridad y la salud durante la crisis del coronavirus. Escuela Andaluza de Salud Pública. https://www.easp.es/web/coronavirusysaludpublica/fake-news-y-bulos-contra-laseguridad-y-la-salud-durante-la-crisis-del-coronavirus/

McNair, B. (2018). Fake News. Falsehood, Fabrication and Fantasy in Journalism. Routledge.

Montero-Liberona, C. y Halpern, D. (2029). Factores que influyen en compartir noticias falsas de salud en línea. El profesional de la información, 28 (3). https://doi.org/10.3145/epi.2019.may.17

Ortiz de Guinea, Y. y Martín-Sáez, J. L. (2019). De los bulos a las fake news. Periodismo, contenidos generados por el usuario y redes sociales. Creatividad y Sociedad. Revista de la Asociación para la Creatividad, (30), 104-124.

Palomo-Torres, B. y Sedano-Amundarain, J. (2018). WhatsApp como herramienta de verificación de fake news. El caso de B de Bulo. Revista Latina de Comunicación Social, 73 (13), 1384-1397. https://doi.org/10.4185/RLCS-2018-1312

Pauner-Chulvi, C. (2018). Noticias falsas y libertad de expresión e información. El control de los contenidos informativos en la red. Teoría y Realidad Constitucional, (41), 297-318. https://doi.org/10.5944/trc.41.2018.22123

Pérez-Tornero, J.M y Varis, T. (2010). Media Literacy and New Humanism. UNESCO Institute for Information Technologies in Education.

Pérez-Rey, J. y Calderón, M.E. (2019). Combatir el ruido de los bulos desde la esencia del periodismo. Interactiva: Revista de la comunicación y el marketing digital, (187), 50-54.

Rand, D., Pennucook, G., McPhetres, J. y Zhang, Y. (2020). Fighting COVID-19 misinformation on social media: Experimental evidence for a scalable accuracy nudge intervention. http://ide.mit.edu/publications/fighting-covid-19-misinformation-social-media-experimentalevidence-scalable-accuracy

Redondo, M. (2018). Verificación digital para periodistas. Manual de bulos y desinformación internacional, Barcelona: Editorial UOC.

Rodríguez-Fernández, L. (2019). Desinformación: retos profesionales para el sector de la comunicación. El profesional de la información, 28 (3), 1-11. https://doi.org/10.3145/epi.2019.may.06 
Santirso, J. (2020, enero 11). Un virus similar al SARS, responsable de la misteriosa neumonía china. El País. https://elpais.com/sociedad/2020/01/09/actualidad/1578556344_366873.html

Silverman, C. (2014). Verificación Handbook. Reino Unido: European Journalism Centre. https://verificationhandbook.com/downloads/verification.handbook.pdf

Shu, K., Sliva, A., Wang, S., Jiliang, T. y Liu, H. (2017). Fake News Detection on Social Media: A Data Mining Perspective. AMC SIGKDD Explorations Newsletter, 19 (1), 22-36. https://doi.org/10.1145/3137597.3137600

Suárez, E. (2020, marzo 31). How fact-chekers are fighting coronavirus misinformation worldwide. Reuters Institute. https://reutersinstitute.politics.ox.ac.uk/risj-review/how-fact-checkers-arefighting-coronavirus-misinformation-worldwide

Ufarte-Ruiz, M.J., Peralta-García, L. y Murcia-Verdú, J. (2018). Fact cheching: un nuevo desafío del periodismo. El profesional de la información, 27(4), 733-741.

https://doi.org/10.3145/epi.2018.jul.02

Valera, S. (2020, abril 22). Cristina Tardáguila: Estamos ante la peor ola de desinformación de la historia". Asociación de la Prensa de Madrid. https://www.apmadrid.es/cristina-tardaguilaestamos-ante-la-peor-ola-de-desinformacion-de-la-historial

Vosoughi, S., Roy, D., Aral, S. (2018). The Spread of true and false news online. Siencie, 359 (6380),146-1151. https://doi.org/10.1126/science.aap9559

Wardle, C. (2017, marzo 14). Noticias falsas. First Draft. https://es.firstdraftnews.org/2017/03/14/noticias-falsas-es-complicado

Wardle, C. y Derakhshan, H. (2017). Information disorder. Toward an interdisciplinary framework for research and policymaking. Estrasburgo: Council of Europe report DGI. https://rm.coe.int/information-disorder-toward-an-interdisciplinary-framework-forresearc/168076277c

Zuckerman, E. (2017, enero 30). Stop saying Fake News, It's not helping. My Heart is in Accra. http://www.ethanzuckerman.com/blog/2017/01/30/stop-saying-fake-news-its-not-helping/

\section{AUTORES:}

\section{Guadalupe Aguado-Guadalupe}

Profesora Titular en el Departamento de Comunicación de la Universidad Carlos III de Madrid. Doctora en Ciencias de la Información por la Universidad Complutense de Madrid. Miembro del grupo de investigación Periodismo y Análisis Social: Evolución, Efectos y Tendencias (PASEET). Su línea de investigación se centra en las tendencias y modelos de negocio de la comunicación en el entorno digital.

maguado@hum.uc3m.es

Indice H: 15 
Orcid ID: https://orcid.org/0000-0001-7314-2403

Google Scholar: $\underline{\text { https://scholar.google.es/citations?user= BxwRkAAAAJ\&hl=es }}$

\section{Itziar Bernaola-Serrano}

Profesora del Departamento de Comunicación de la Universidad Carlos III de Madrid. Doctoranda en el programa de Investigación en Medios de Comunicación de la Universidad Carlos III de Madrid. Su línea de investigación se centra en los procesos verificación, agenda-setting y uso de fuentes periodísticas.

ibernaol@hum.uc3m.es

\section{Indice H: 1}

Orcid ID: https://orcid.org/0000-0002-1607-2661

Google Scholar: https://scholar.google.es/citations?user=K6PQSfMAAAAJ\&hl=es\&oi=ao 